\title{
Multiband MIMO Antenna System with Parasitic Elements for WLAN and WiMAX Application
}

\author{
Reza Karimian and Hamed Tadayon \\ Antenna and Microwave Research Laboratory, EE Department, Iran University of Science and Technology, 1684613114 Tehran, Iran \\ Correspondence should be addressed to Reza Karimian; reza.bahnemiri@gmail.com
}

Received 10 July 2013; Revised 5 November 2013; Accepted 8 November 2013

Academic Editor: Ahmad Safaai-Jazi

Copyright (C) 2013 R. Karimian and H. Tadayon. This is an open access article distributed under the Creative Commons Attribution License, which permits unrestricted use, distribution, and reproduction in any medium, provided the original work is properly cited.

\begin{abstract}
A new microstrip slot antenna with parasitic elements has been presented in this paper. The proposed antenna is composed of a microstrip feed line, a ground plane on which some simple slots are etched, and parasitic elements. Simulation results show that the antenna structure allows for the independent adjustment of each frequency. A two-element array configuration of this antenna for MIMO application is investigated as well. For comparison between simulation and measurement result both single and array configurations have been fabricated. The measurement result exhibits good radiation performance in terms of return loss, low mutual coupling, and compactness.
\end{abstract}

\section{Introduction}

Recent researches show that MIMO system can provide substantial improvement in system capacity with the traditional SISO communication systems [1]. The recent increase in demand for high quality wireless communications has induced the development of various multiantennas systems for WLAN and WiMAX applications such as diversity and MIMO systems. Because of the advantages of low manufacturing cost, light weight, easy integration, and easy fabrication, the printed antenna becomes a good candidate for these applications.

In order to meet the WLAN and WiMAX standards simultaneously, multiband antennas are required. Many related researches have been done for such demands. Slot antennas are often adopted to realize multiband operation owing to their easy integrating with ground plane, such as inverted Ushaped slot [2] and triband slot antenna with the pair of Tshaped strips [3]. Patch antennas for multiband operations were also presented [4-8]. Coplanar waveguide antennas (CPW), such as dual-band rhombus slot [9], monopole antenna employing T-shaped quasi-self-complimentary resonators [10], parasitically loaded CPW-fed [11], and planar monopole [12], are also applied to realize multiband operation due to their low cost and omni-directional radiation pattern.
Various printed antennas suitable for MIMO applications have been proposed as well [13-16]. The design of a triband Eshaped monopole antenna loaded with narrow slots is given in [13]. A four-element L-shaped slot antenna with L-shaped slit has been presented in [14]. Also a two-element MIMO antenna for wireless applications is presented in [16].

In this paper, a new design of planar antenna with parasitic strip suitable for MIMO application is presented. Compared to the antennas in [2-12], the proposed antenna in this paper not only achieves triple bands simultaneously but also has a rather simple structure that is easy to fabricate. Meanwhile, the proposed antenna structure also allows for the independent adjustment or tuning of each frequency of interest within certain limits, which is important aspect for manufacturing. Also in comparison with [13-15] the proposed array offers an enhanced performance in terms of operation frequency bands with better isolation in addition to the advantage of smaller size. Details of the proposed design are described. Simulation and measurement result for both single and array antenna is presented. The measured results show good agreement with the simulated ones.

\section{Antenna Geometry and Design Procedure}

Figure 1 shows the geometry with design parameters of the proposed multiband antenna which is printed on a low 


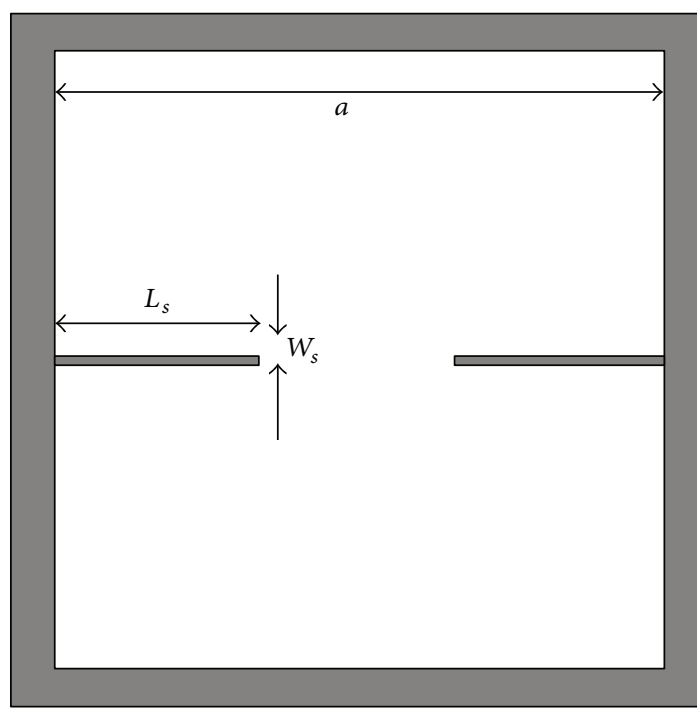

(a)

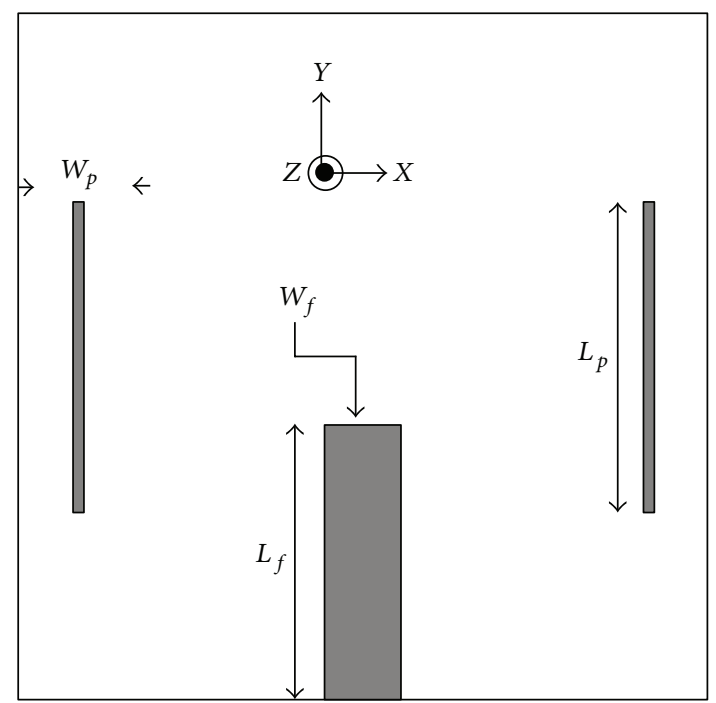

(b)

Figure 1: Configuration of an antenna element, (a) front view and (b) back view.

cost FR4 substrate with dielectric $\varepsilon_{r}=4.4$, loss tangent $\tan \delta=0.02$, and thickness $1.6 \mathrm{~mm}$. The overall dimension of the antenna is $28 \times 28 \mathrm{~mm}^{2}$. Figure 2 exhibits the design evolution of the proposed multiband antenna on simulated frequency response of return loss. It begins with a conventional slot antenna $25(\mathrm{a}) \times 25(\mathrm{a}) \mathrm{mm}^{2}$ (denoted as Case I) which is about $\lambda / 2=62 \mathrm{~mm}$ with respect to the first operation band. Due to higher resonant mode (second resonant frequency in this case) in Case I, in addition of desired frequency at $2.4 \mathrm{GHz}$, there is another resonant frequency at the frequency of $4.3 \mathrm{GHz} \cong .085 \lambda$. As it has been discussed in [14] at the second resonance, the pattern starts to undulate. Therefore the second resonant frequency cannot be used for omni-directional goals.

The second resonant frequency at $3.5 \mathrm{GHz}$ can be achieved with introducing a pair of symmetrical horizontal strips at the middle of wide slot. The strips generate current flow path at the second resonant frequency, which can be assumed as [17]

$$
f=\frac{c}{4 L_{s} \cdot \sqrt{\varepsilon}}, \quad \varepsilon=\frac{\varepsilon_{r}+1}{2},
$$

where $L_{s}$ is the length of horizontal strip, $\varepsilon$ is the effective dielectric constant, and $c$ is the speed of light in free space. Case II in Figure 2 represents that the second resonant frequency at $3.5 \mathrm{GHz}$ is achieved with little impact on the first designed frequency. Two-strip patch as parasitic element is etched on the bottom portion of FR4 substrate in order to achieve third resonant frequency at $5.8 \mathrm{GHz}$. Case III in Figure 2 depicts that the third resonant has been achieved while other frequencies are almost constant. Note that at all three cases the antennas are fed through a $50 \mathrm{ohm}$ microstrip patch at the bottom side of antenna.

Figure 3 represents surface current distribution at $2.4 \mathrm{GHz}$ and $4.3 \mathrm{GHz}$. The difference between $0.5 \lambda$ and
$0.85 \lambda$ can be clearly seen from the figure. Surface current distribution at $2.4 \mathrm{GHz}$ has two maximum and a minimum representing half-wave slot antenna (Figures 3(a) and 3(b)) representing $0.85 \lambda$ (almost two maximum and two minimum). Note that this figure is related to Case II.

In Figure 4(a), the current flows along the edge of the strips upward to the upper side of the rectangular slot. Therefore, the embedded strips in the slot mainly generate the middle frequency. Similarly in Figure 4(b), the current centralizes in the region nearby the parasitic strip that generates the highest frequency.

A comprehensive parametric study was carried out to get insight on the effect of various antenna parameters that enable optimization of the antenna's performance.

The return loss characteristics of different $L_{s}$ are demonstrated in Figure 5. As the length of horizontal strip $\left(L_{s}\right)$ increases from $6 \mathrm{~mm}$ to $9 \mathrm{~mm}$, the upper edge frequency of the antenna shifts down while leaving the lower and upper edge frequency almost unchanged. The parasitic elements have a strong effect on the upper frequency characteristic of the antenna. Figure 6 displays that the upper resonance frequency is mainly determined by the dimension of $L_{p}$, while the other resonant frequencies are almost unchanged. The longer the $L_{p}$ is, the lower the upper resonance frequency will be.

By fixing the optimum parameters of the proposed antenna, good impedance matching through the operation bands for WLAN and WiMAX applications can be achieved. The parameters are set as follows: $a=25 \mathrm{~mm}, L_{s}=8.6 \mathrm{~mm}$, $W_{s}=0.4 \mathrm{~mm}, L_{p}=13 \mathrm{~mm}, W_{p}=0.3 \mathrm{~mm}, L_{f}=11.5 \mathrm{~mm}$, and $W_{f}=3 \mathrm{~mm}$.

The comparison between the simulated and measured reflection coefficient characteristic of the proposed antenna obtained by using CST2010 and the Agilent E8361C vector network analyzer is shown in Figure 7. Apparently, the measured return losses below $-10 \mathrm{~dB}$ bandwidth range between 


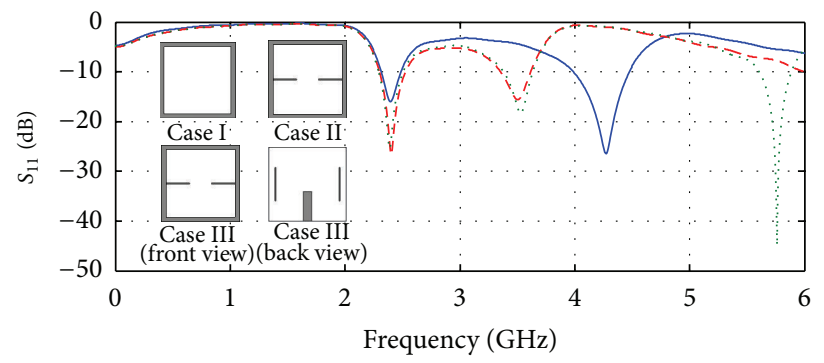

W/O patch and parasitic elements
- - With patch and W/O parasitic elements
.... Proposed antenna

FIGURE 2: Design procedure of the proposed antenna. Case I: single band, Case II: dual-band, and Case III: triband operation.

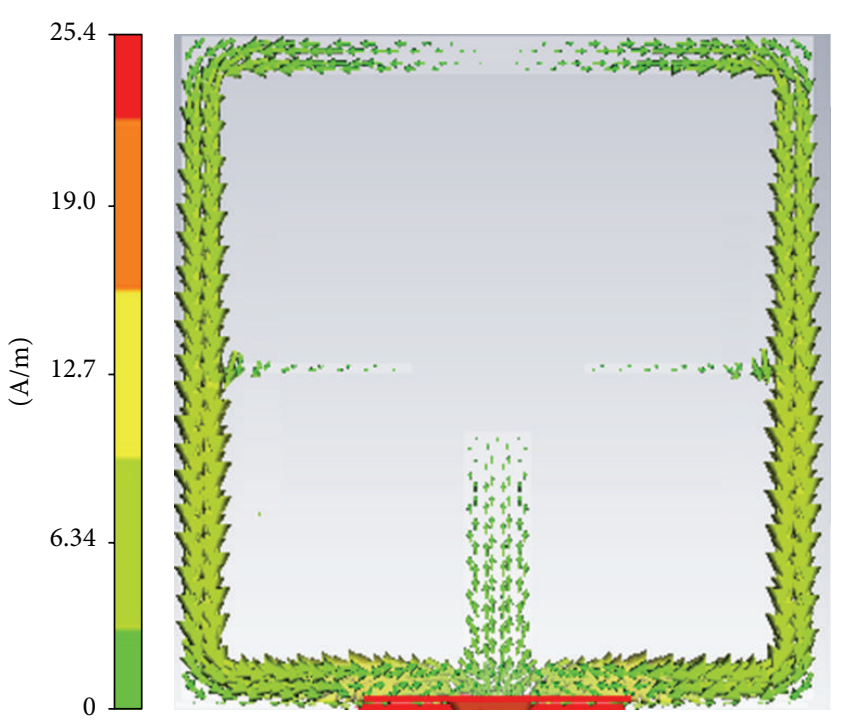

(a)

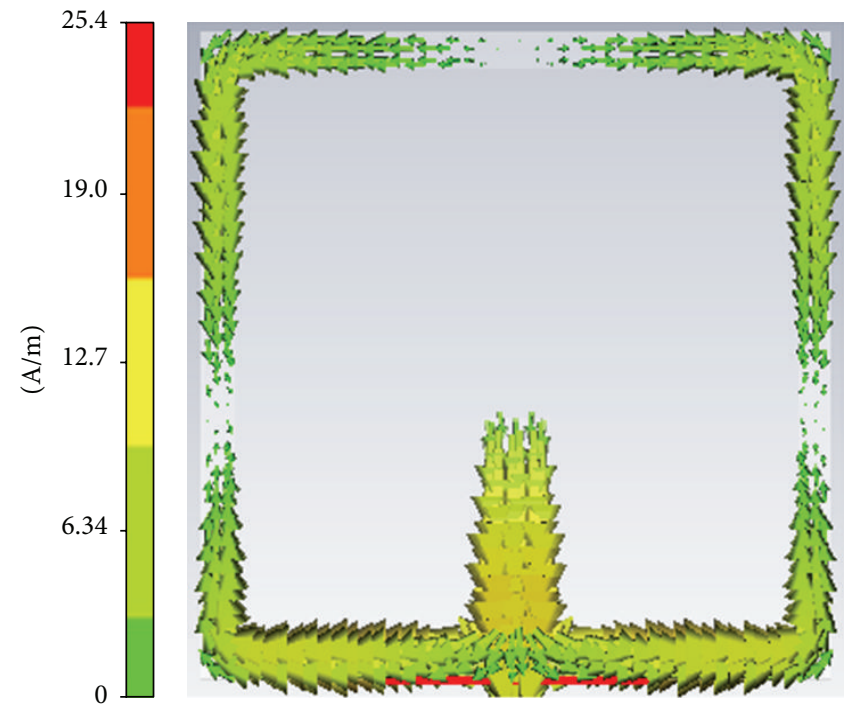

(b)

Figure 3: Surface current distribution (a) $2.4 \mathrm{GHz}$ and (b) $4.3 \mathrm{GHz}$.

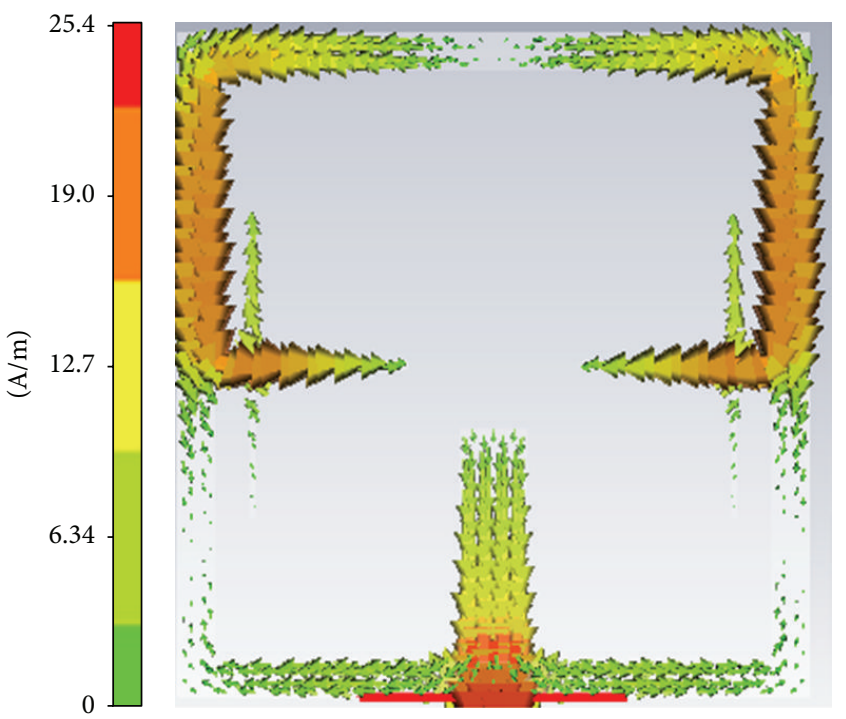

(a)
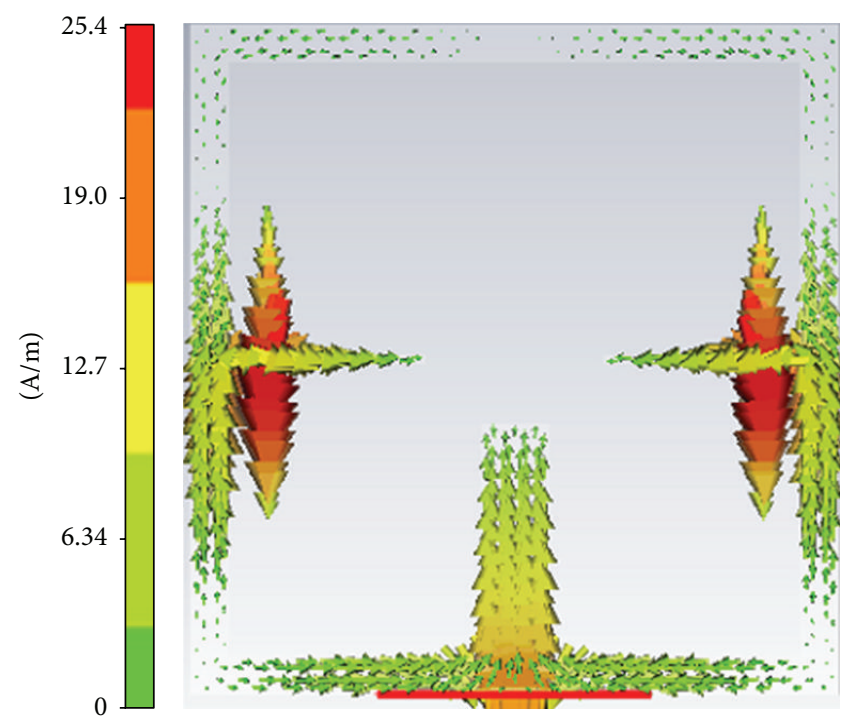

(b)

FIgURE 4: Surface current distribution (a) $3.5 \mathrm{GHz}$ and (b) $5.8 \mathrm{GHz}$. 


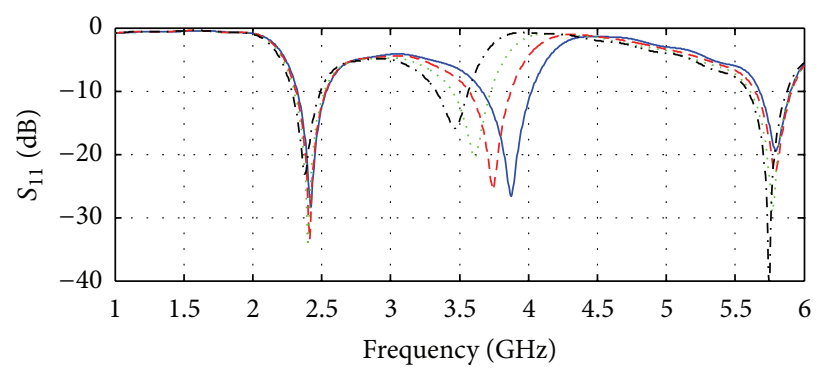

$$
\begin{array}{ll}
L_{s} & =6 \mathrm{~mm} \\
-\ldots & L_{s}=7 \mathrm{~mm}
\end{array}
$$

FIgURE 5: Simulated return loss with different $L_{s}$.

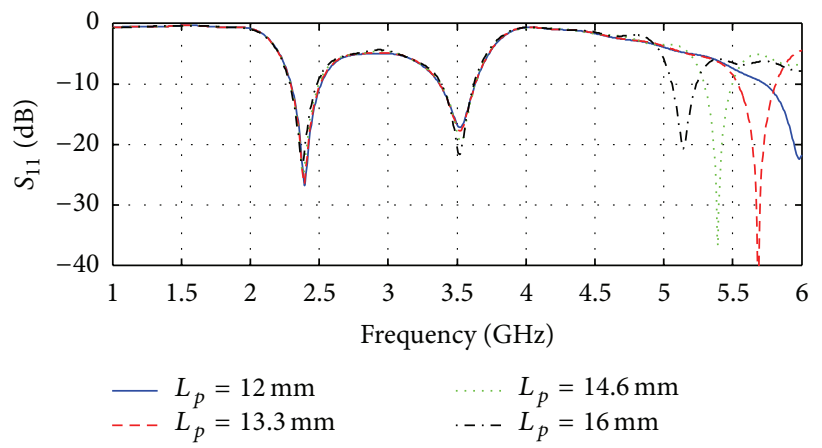

FIGURE 6: Simulated return loss with different $L_{p}$.

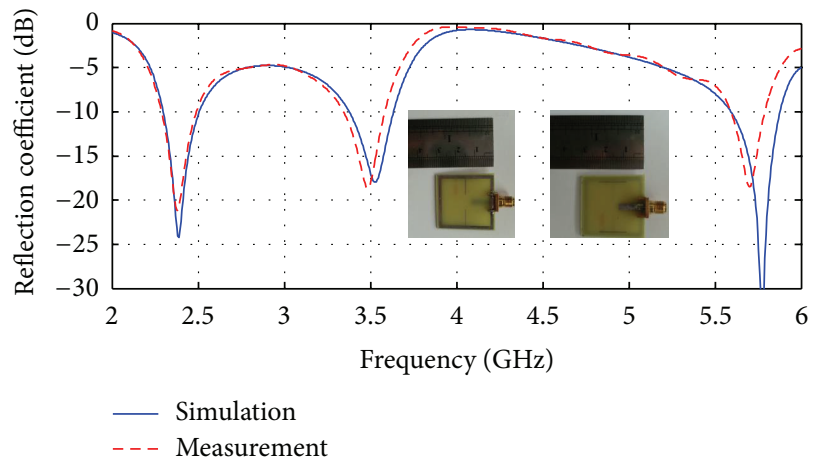

FIGURE 7: Simulated and measured reflection coefficient characteristic of proposed antenna element.

2.3-2.52 GHz, 3.4-3.62 GHz, and 5.6-5.95 GHz, which show approximate agreement with the simulated result. Some slight discrepancies between them may be attributed to measurement errors, inaccuracies in the fabrication process, and the effect of the SMA connector.

\section{Integration of Two MIMO Element}

The antenna element presented in Section 2 shows that it is suitable for WLAN and WiMAX application and can be arrayed for use in MIMO application.

The primary aim of MIMO antenna design is to reduce correlation between received signals. A significant parameter for the correlation is the mutual coupling. One of the most critical parameters affecting mutual coupling and correlation is due to common ground plane, sharing the surface current, which can be reduced by etching slot into the ground plane among the slot antenna. The second parameter that affects the correlation between the received signals is the polarization of the antennas, polarization diversity.

This paper, based on orthogonal polarization diversity and separated common ground plane, introduces a new low profile two-element MIMO antenna with good isolation and simple to fabricate.

3.1. Impedance Performance. Figure 8 depicts a photograph of the fabricated proposed array antenna. The antenna elements are orthogonal to each other in order to make 


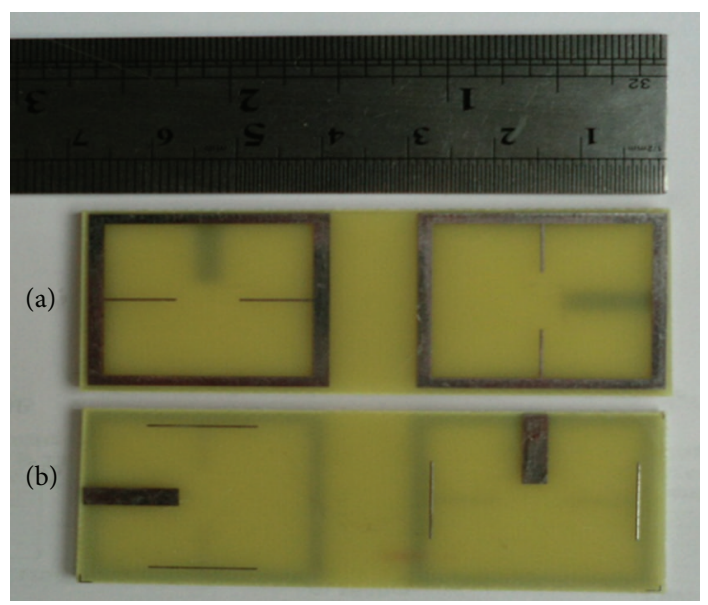

FIGURE 8: Prototype of fabricated MIMO antenna, (a) front view and (b) bottom view.

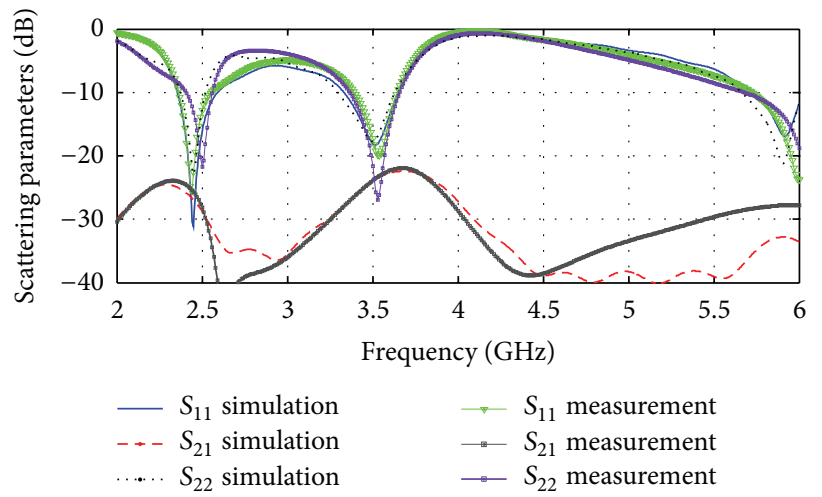

FIGURE 9: Comparison between simulated and measured scattering parameters for the proposed MIMO array.

polarization diversity. A rectangular slot with the width of less than $0.1 \lambda$ ( $\lambda$ is the wavelength of lowest resonant frequency) has been etched on ground plane of the antenna array to separate the common ground plane. The simulated and measured $S$-parameters are in a good agreement as observed in Figure 9. An E8361C vector network analyzer was used to measure the scattering parameters characteristic of the fabricated MIMO array in an anechoic chamber. In this measurement one port is excited and the other port was terminated by a $50 \Omega$ matching load. Mutual coupling better than $-22 \mathrm{~dB}$ has been achieved for the antenna spacing less than $0.1 \lambda(10 \mathrm{~mm})$. In comparison with [13], this antenna array configuration improved isolation more than $8 \mathrm{~dB}$ with the advantage of compact size.

3.2. Radiation Performance. Measured radiation pattern for three principal planes and for three resonant frequencies, when one element was excited and the other antenna element was matched by a standard $50 \Omega$ matching load, has been demonstrated in Figure 10. The orientation of the antenna with respect to coordinate system is clarified in Figure 1. One can see that nearly omnidirectional pattern has been achieved at all three frequencies (Table 1). There are no deep nulls in any direction. This is an important factor when antenna has been used for MIMO application [14].
TABLE 1: Simulated peak gain and radiation efficiency results.

\begin{tabular}{lccc}
\hline Frequency $(\mathrm{GHz})$ & 2.4 & 3.5 & 5.2 \\
Gain $(\mathrm{dBi})$ & 1.98 & 3.1 & 1.6 \\
Efficiency $(\%)$ & 75 & 87 & 64 \\
\hline
\end{tabular}

3.3. Diversity Performance. Envelope correlation coefficient is an important parameter to measure the diversity gain of a MIMO system. Generally, low envelope correlation always leads to high diversity gain [14]. For a two-antenna system, a simple formula can be used to calculate envelope correlation coefficient [18] as follows:

$$
\rho=\frac{\left|\mathbf{S}_{11}^{*} \mathbf{S}_{12}+\mathbf{S}_{21}^{*} \mathbf{S}_{22}\right|^{2}}{\left(1-\left|\mathbf{S}_{11}\right|^{2}-\left|\mathbf{S}_{21}\right|^{2}\right)\left(1-\left|\mathbf{S}_{22}\right|^{2}-\left|\mathbf{S}_{12}\right|^{2}\right)} .
$$

The calculated result of the proposed antenna is exhibited in Figure 11. It shows that the desired operation band of the proposed antenna has an envelope correlation coefficient less than 0.04 , which is practically acceptable.

Low mutual coupling, good impedance matching, low envelope correlation, and stable radiation patterns in three principal planes confirm that the proposed MIMO array is 


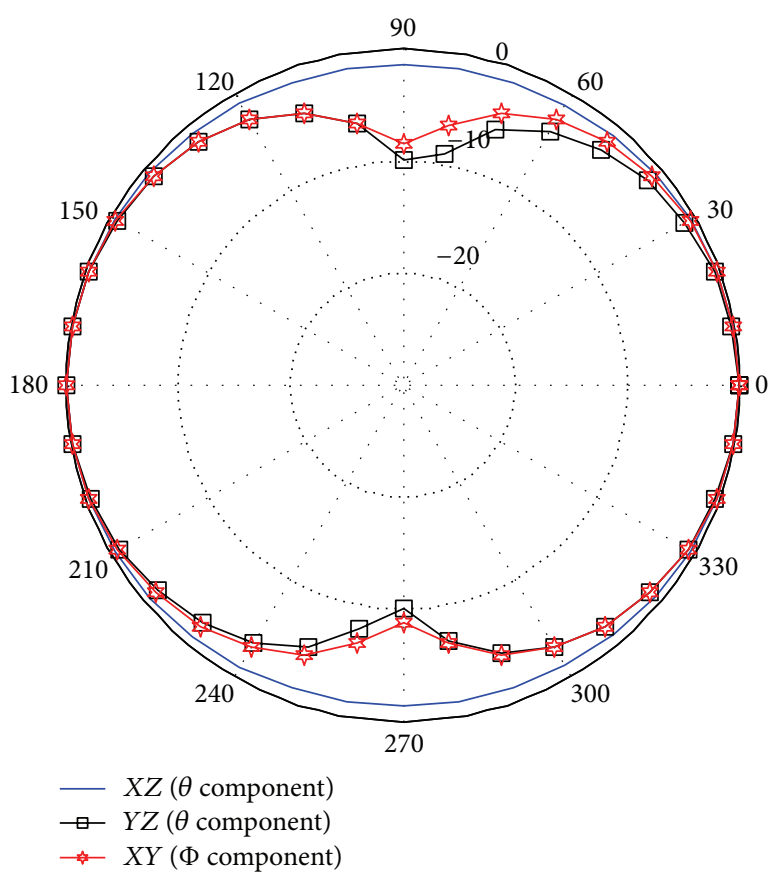

(a)

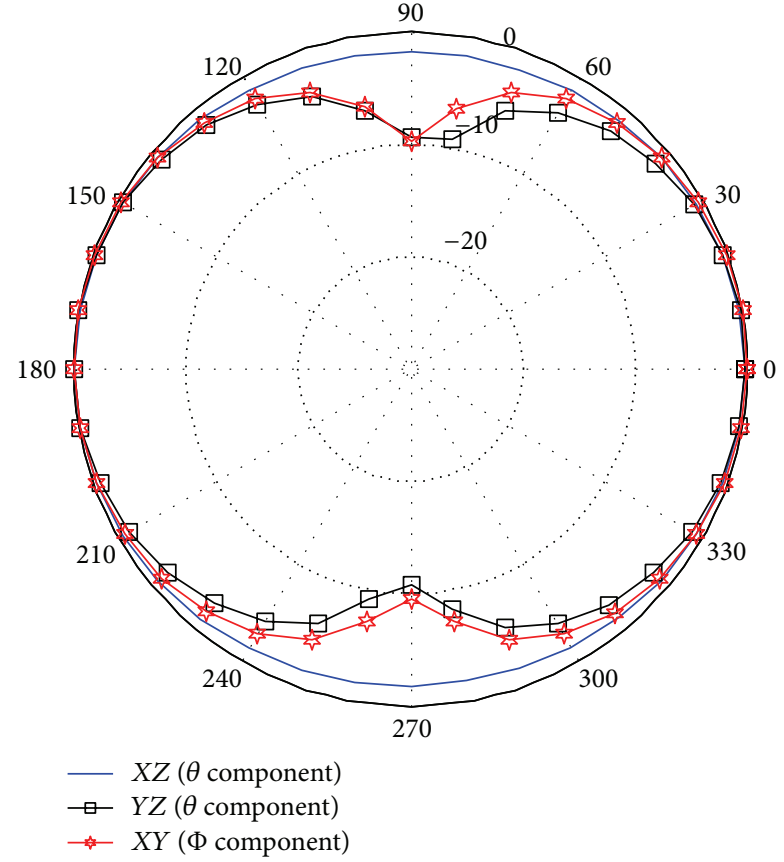

(b)

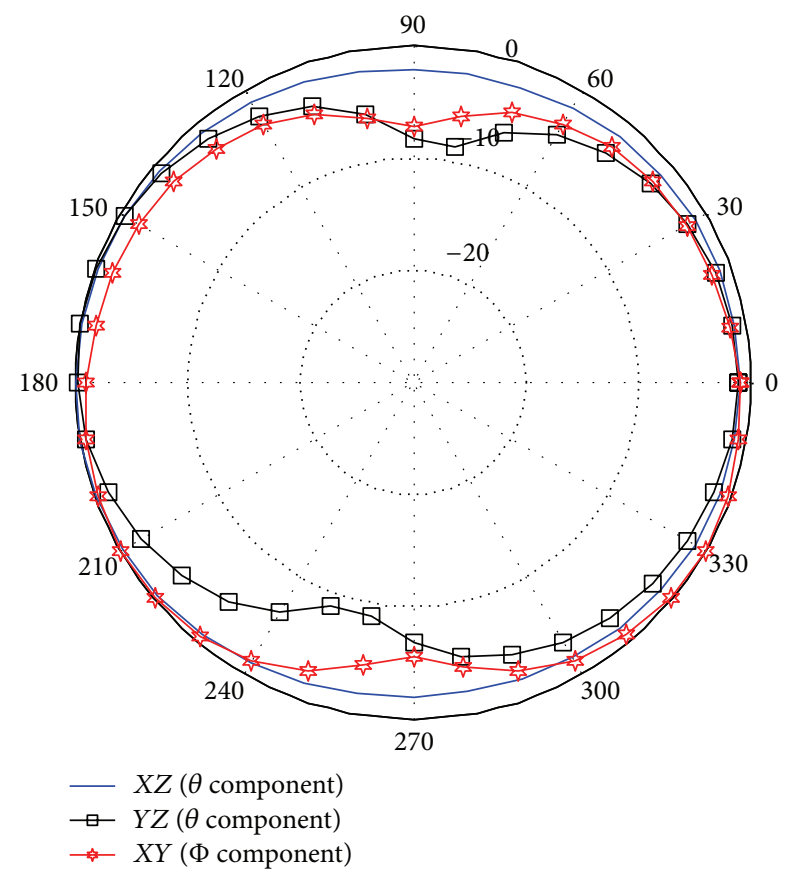

(c)

FIGURE 10: Measured radiation pattern for three principle planes (a) $2.4 \mathrm{GHz}$, (b) $3.5 \mathrm{GHz}$ and (c) $5.8 \mathrm{GHz}$.

a good candidate for use in WLAN and WiMAX MIMO systems.

\section{Conclusion}

A compact planar multiband antenna is developed in this work. The proposed antenna utilized a pair of horizontal strips and a pair of vertical strips patch as parasitic element to achieve second and third resonant frequency, while the wideband slot provides the first resonant frequency at $2.4 \mathrm{GHz}$. The current distributions excited at resonant frequency reveals that the proposed antenna operates at halfwave guided length mode. Parametric study shows that the proposed antenna structure allows for the independent adjustment or tuning of each frequency of interest within certain limits. A particular combination of two such elements 


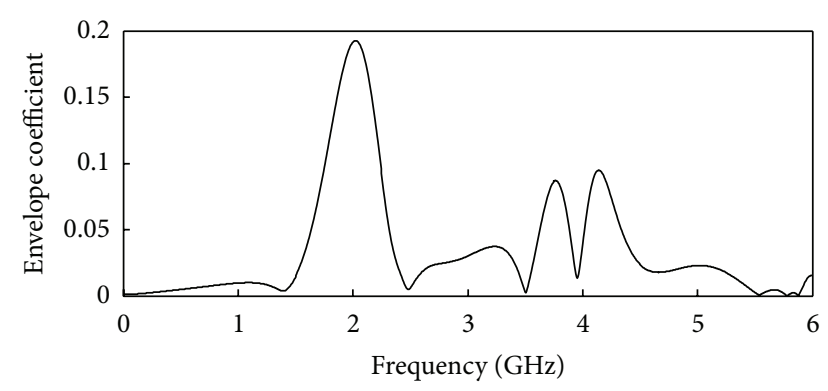

Figure 11: Measured envelope correlation of the proposed multiband antenna.

has been used for MIMO application. The measured return loss complies with the frequency of WLAN and WiMAX application. The MIMO antenna array provides better than $-22 \mathrm{~dB}$ mutual coupling, envelope correlation of lower than 0.01 , and stable omnidirectional patterns at all three frequencies.

\section{References}

[1] Y. Ding, Z. Du, K. Gong, and Z. Feng, "A novel dual-band printed diversity antenna for mobile terminals," IEEE Transactions on Antennas and Propagation, vol. 55, no. 7, pp. 2088-2096, 2007.

[2] L. Xiong and P. Gao, "A compact triple-band wide-slot antenna for WLAN/WiMAX applications," Journal of Electromagnetic Wave and Application, vol. 26, no. 7, pp. 895-903, 2012.

[3] X. Q. Zhang, Y. C. Jiao, and W. H. Wang, "Compact wide triband slot antenna for WLAN/WiMAX applications," Electronics Letters, vol. 48, no. 2, pp. 64-65, 2012.

[4] K. He, R.-X. Wang, Y.-F. Wang, and B.-H. Sun, "Compact tri-band claw-shaped monopole antenna for WLAN/WiMAX applications," Journal of Electromagnetic Waves and Applications, vol. 25, no. 5-6, pp. 869-877, 2011.

[5] Y. Han, Y.-Z. Yin, Y.-Q. Wei, Y. Zhao, B. Li, and X.-N. Li, "A novel triple-band monopole antenna with double coupled C-shaped strips for WLAN/WiMAX applications," Journal of Electromagnetic Waves and Applications, vol. 25, no. 8-9, pp. 1308-1316, 2011.

[6] W.-C. Liu, M. Ghavami, and W.-C. Chung, "Triple-frequency meandered monopole antenna with shorted parasitic strips for wireless application," IET Microwaves, Antennas and Propagation, vol. 3, no. 7, pp. 1110-1117, 2009.

[7] L. Peng, C.-L. Ruan, and X.-H. Wu, "Design and operation of dual/triple-band asymmetric M-shaped microstrip patch antennas," IEEE Antennas and Wireless Propagation Letters, vol. 9, pp. 1069-1072, 2010.

[8] J. Pei, A.-G. Wang, S. Gao, and W. Leng, "Miniaturized tripleband antenna with a defected ground plane for WLAN/ WiMAX applications," IEEE Antennas and Wireless Propagation Letters, vol. 10, pp. 298-301, 2011.

[9] C.-C. Lin, E.-Z. Yu, and C.-Y. Huang, "Dual-band rhombus slot antenna fed by CPW for WLAN applications," IEEE Antennas and Wireless Propagation Letters, vol. 11, pp. 362-364, 2012.

[10] W. Hu, Y.-Z. Yin, S.-T. Fan, X. Yang, Y. Zhao, and J.-H. Yang, "Compact octagonal monopole antenna employing T-shaped quasi-self-complimentary resonators for tri-band operation,"
Journal of Electromagnetic Waves and Applications, vol. 25, no. 14-15, pp. 1953-1962, 2011.

[11] W.-C. Liu, C.-M. Wu, and Y.-J. Tseng, "Parasitically loaded CPW-fed monopole antenna for broadband operation," IEEE Transactions on Antennas and Propagation, vol. 59, no. 6, pp. 2415-2419, 2011.

[12] H.-W. Liu, C.-H. Ku, and C.-F. Yang, "Novel CPW-fed planar monopole antenna for WiMAX/WLAN applications," IEEE Antennas and Wireless Propagation Letters, vol. 9, pp. 240-243, 2010.

[13] S. M. A. Nezhad and H. R. Hassani, "A novel triband E-shaped printed monopole antenna for MIMO application," IEEE Antennas and Wireless Propagation Letters, vol. 9, pp. 576-579, 2010.

[14] R. Karimian, M. Soleimani, and S. M. Hashemi, "Tri-band four elements MIMO antenna system for WLAN and WiMAX application," Journal of Electromagnetic Waves and Applications, vol. 26, no. 17-18, pp. 2348-2357, 2012.

[15] R. Karimian, H. Oraizi, S. Fakhte, and M. Farahani, "Novel F-shaped quad-band printed slot antenna for WLAN and WiMAX MIMO systems," IEEE Antennas and Wireless Propagation Letters, vol. 12, pp. 405-408, 2013.

[16] M. S. Sharawi, A. B. Numan, and D. N. Aloi, "Isolation improvement in a dual-band dual-element mimo antenna system using capacitively loaded loops loaded loops," Progress in Electromagnetic Research, vol. 134, pp. 247-266, 2013.

[17] C. M. Li, K. Wang, and C. K. Chen, "Small tri-band monopole antenna for WLAN/WiMAX applications," Journal of Electromagnetic Waves and Applications, vol. 25, pp. 1297-1307, 2011.

[18] J. Thaysen and K. B. Jakobsen, "Envelope correlation in (N, N) mimo antenna array from scattering parameters," Microwave and Optical Technology Letters, vol. 48, no. 5, pp. 832-834, 2006. 

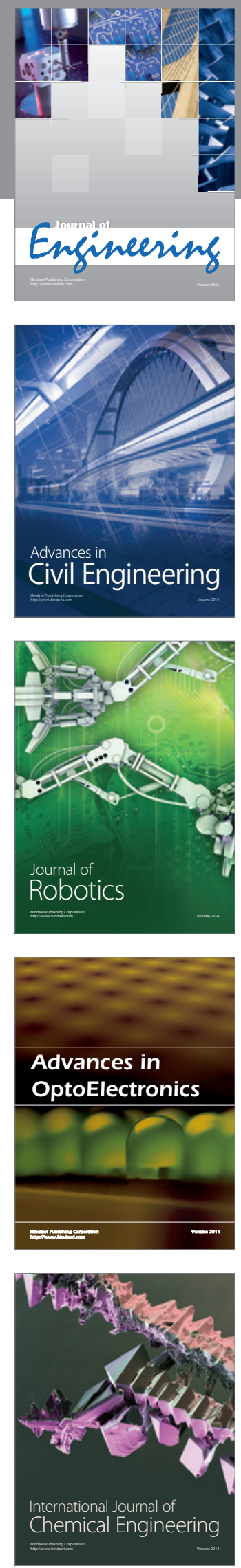

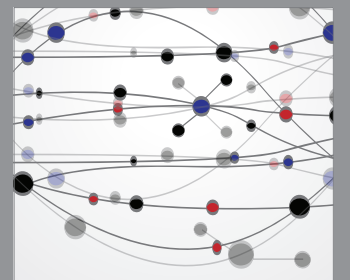

The Scientific World Journal
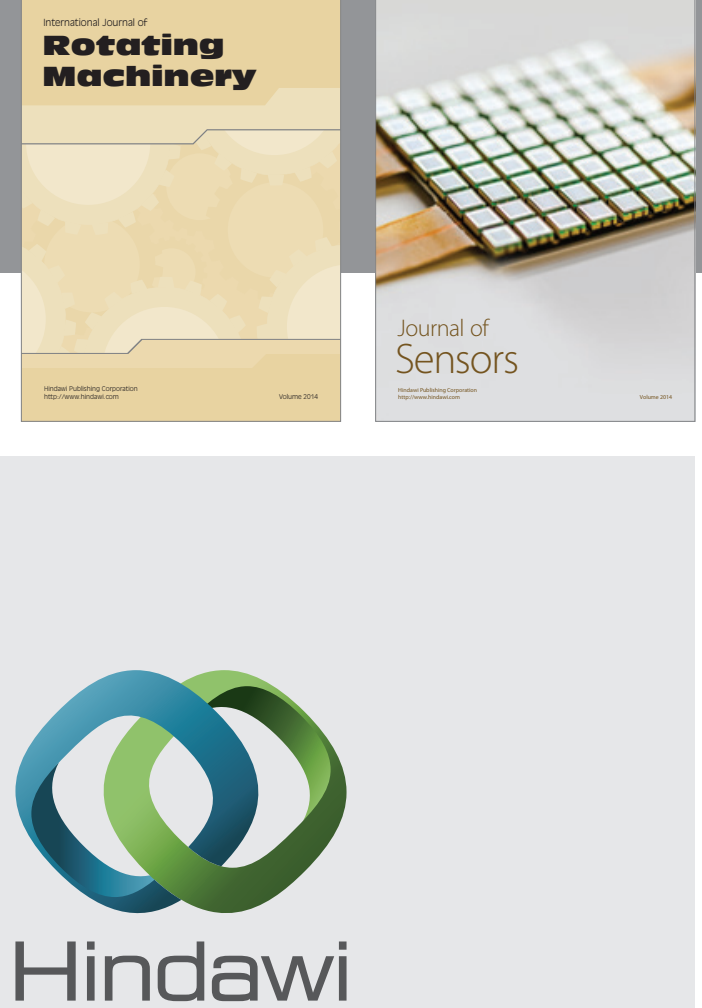

Submit your manuscripts at http://www.hindawi.com
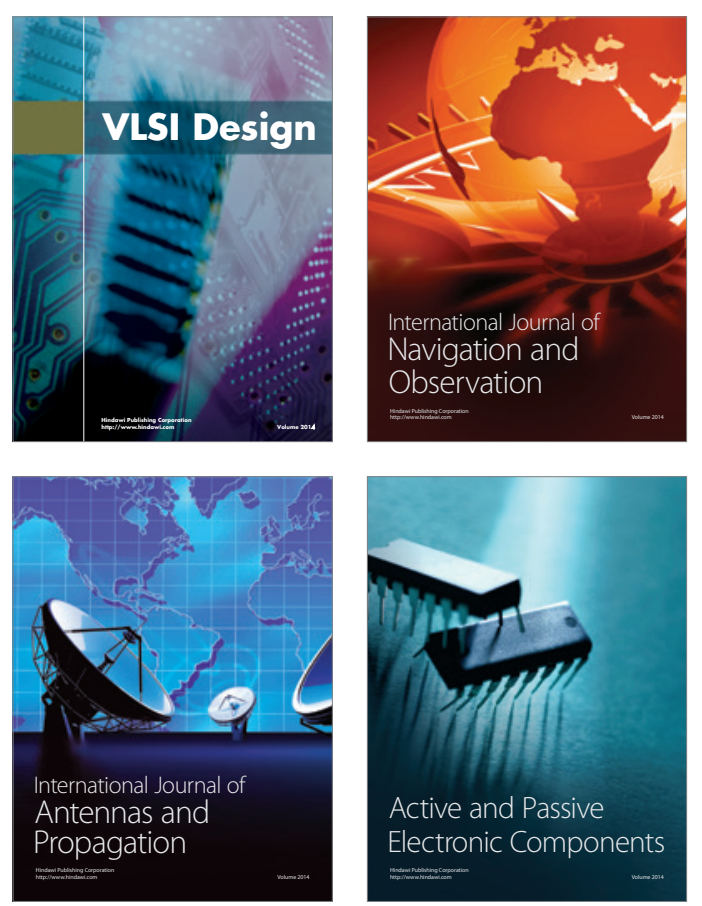
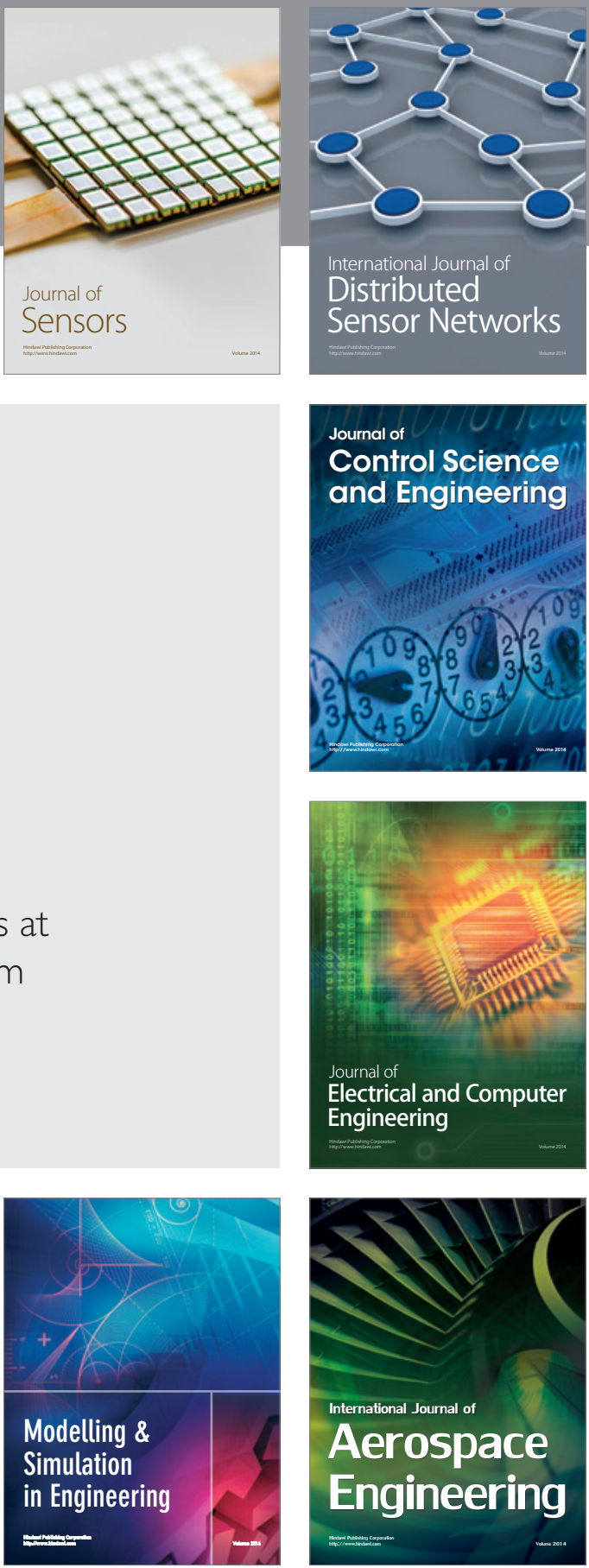

Journal of

Control Science

and Engineering
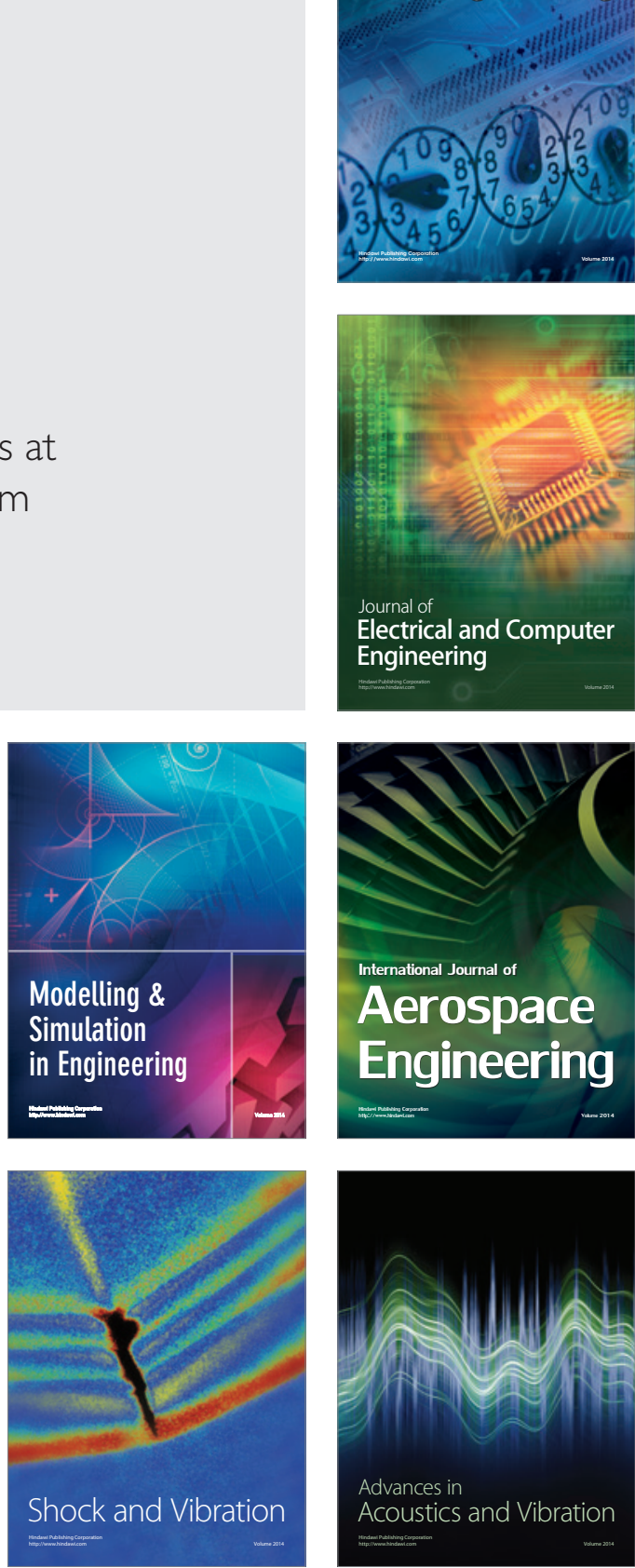